\title{
CRONOTOPOS Y DINÁMICA ENUNCIATIVA EN LOS MODOS PARTICULARES DEL DISCURSO ARTÍSTICO-VISUAL
}

\author{
Por: \\ William Álvarez Ramírez ${ }^{1}$ \\ Profesor del Departamento de Filosofía \\ Universidad del Valle \\ william.alvarez@correounivalle.edu.co
}

\section{Resumen:}

Este trabajo considera la conformación de los lenguajes del arte, en el contexto de una teoría de la enunciación visual, en el cual enunciado es dado por individuo y dirigido hacia un individuo. Hay en él una orientación intencional, que dota de sentido los enunciados plástico-visuales, pues es en su relacionalidad construida que se reconoce todo el contexto situacional, así como las múltiples voces que pueblan el discurso estético. Lo característico y constitutivo del enunciado es su "orientación hacia alguien”, un enunciado tiene autor y destinatario. En el constructo central de M. Bajtin los conceptos polifonía y dialógico, están implicados por su noción de direccionalidad como "cualidad de dirigirse a otro" sin la cual, el enunciado no puede darse. De esta manera, es el carácter contextual, relacional e intencional del objeto de comunicación, en este caso la obra visual, lo que hace que los hombres estén signados por los modos de representación de los otros.

Palabras claves: lenguajes del arte, arte conceptual, enunciación

\begin{abstract}
:
This paper considers the formation of the languages of art, in the context of a statement visual theory, in which the statement is given by an individual and directed towards an individual. It has an intentional orientation that gives meaning to the plastic-visual statements, as it is in its constructed relationality that all the situational context is recognized, as well as the multiple voices that populate the aesthetic speech. The characteristics and constitutive of the sentence is its "orientation towards somebody", so a statement has an author and a recipient. In M. Bajtin's main discourse the concepts of polyphonic and dialogues are implied by their notion of directionality as a "quality of telling to someone" without which, the statement cannot occur. Thus the character is contextual, relational and intentional communication object, in this case, the visual work, which makes men to be signed by the ways of others' representation.
\end{abstract}

Key words: art languages, conceptual art, enunciation. 


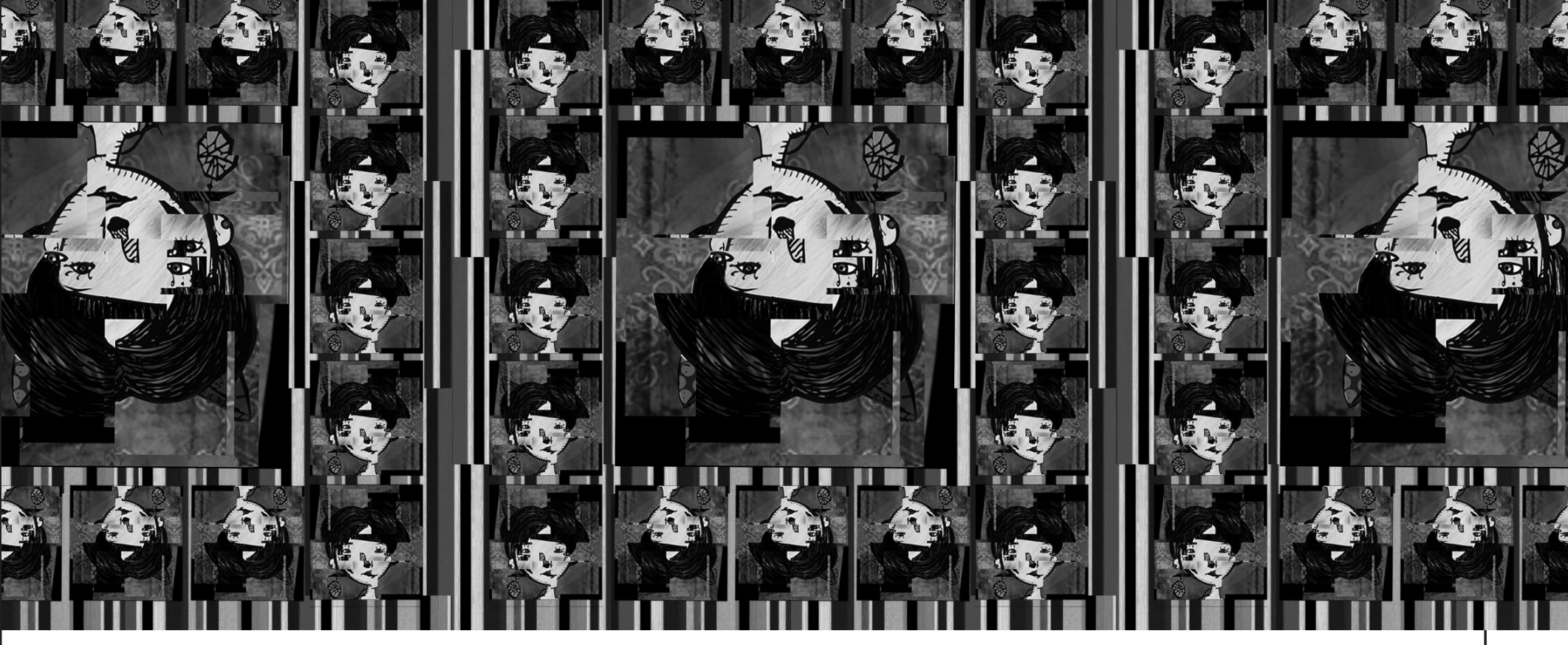

\section{El lenguaje del arte: mundos posibles}

El arte en tanto objetivación del hombre en el mundo es un hecho comunicativo y se constituye en los modos de lenguaje. Éste es consecuencia de la necesidad de aprehensión y comprensión del entorno o mundo de relaciones múltiples en las cuales el hombre, desde su sensibilidad que pone su cuerpo como centro, actúa y realiza su existencia. De este modo las formas y los esquemas lógico-formales que dinamizan el lenguaje artístico conforman los sistemas particulares del arte, que expresan los modos singulares tanto de cada sujeto como de sus imaginarios y del mundo de la vida del cual emerge su sensibilidad. En este sentido se comprende el interés de las vanguardias artísticas de la primera mitad del siglo XX por la investigación de los límites entre los lenguajes artísticos que les son propios, por las técnicas y procedimientos, al tiempo que se definen las diferencias y particularidades que determinan su especificidad. Las vanguardias del arte moderno se definieron fundamentalmente conceptuales y las obras de arte se determinan según los conceptos que refieren. (Stangos, 1996; Hofmann, 1995).

El desarrollo del arte contemporáneo señala el paso entre la "morfología de la apariencia sensible”, característica de la autoconciencia plástico-visual desde la pintura del Renacimiento hasta las vanguardias artístico-visuales del siglo XX, a la lógica de su "función" (del arte) sustentada en el sentido del concepto o idea. Habrá de distinguirse entonces, la investigación del sentido de los términos y las expresiones, de una parte, y de las cosas y asuntos que se refieren con dichos términos y expresiones, en la acepción establecida por von Wright, en Valor, Norma y Acción (1999). El desarrollo de la identidad de los lenguajes plásticos-visuales que tienen su condición y a su vez la expresión en la autorreferencia (inicialmente temática, es decir, según el contenido), llevan implicado, desde la ruptura establecida por el impresionismo hasta 1917 con la instalación de La fuente de R. Mutt (Marcel Ducham), la transformación, o mejor, la instauración de un nuevo paradigma en la naturaleza del arte y, como condición de su realización y de su función, se requiere de la idea, enunciado o concepto en el contexto de una estética crítica y semánticoanalítico de los términos. 
Así pues se explica con el desarrollo del arte conceptual, cómo "los diversos elementos físicos utilizados denuncian una intención reductora de la obra de arte en su sentido tradicional. El arte conceptual exige nuevos medios de elaboración." (Marchan Fiz, 1986:251). Los medios de realización de la idea artística pueden ser: fotografías, películas, cintas magnetofónicas, obras telefónicas, documentos, entrevistas, videos. La tendencia más radical de la eliminación del objeto dentro del arte conceptual se expresa en la obra teórica del artista Joseph Kosuth, en su trabajo con el grupo Art \& Langage. En La idea como arte. Documentos sobre el arte conceptual. Kosuth advierte que la función del arte, como pregunta e intención fue planteada por Marcel Duchamp

“CCuál es la función del arte o su naturaleza? Si proseguimos nuestra analogía de las formas que el arte toma al ser lenguaje del arte, podremos comprender que una obra es una especie de proposición presentada dentro de su contexto como comentario artístico. La analogía que quiero establecer se refiere a la condición artística y la proposición analítica (en el sentido de Kant). Las obras son proposiciones analíticas. Una obra de arte es una tautología por ser una presentación de las intenciones del artista" (Kosuth, 1977: 60-81).

Esta condición de tautología es la misma que ha establecido Wittgenstein en las proposiciones 4.461 y 4.462 del Tractatus logico-philosophicus: "La tautología carece de posibilidades veritativas dado que es incondicionalmente verdadera." -Dicho de otro modo, la obra de arte no está sujeta a verificación en su valor de verdad- "Tautología y contradicción no son figuras (imágenes) de la realidad. No representan ningún posible estado de cosas. Porque aquélla permite cualquier posible estado de cosas, ésta ninguno. En la tautología las condiciones de concordancia (Übereinstimmung) con el mundo -las relaciones representativas- se neutralizan entre sí, de modo que no está en relación representativa alguna con la realidad.” (Wittgenstein, 1994:88-89).

Es aquí en este ámbito que se comprende la hermenéutica que se opera desde la resignificación que de la estética kantiana y de su noción de la realización de la conciencia estética como un juego libre de facultades del ánimo. Se presenta de este modo, utilizando el lenguaje de Kant, un "giro copernicano" en el arte. Se trata de giro tanto hermenéutico como analítico que se constituye porque se da mayor relevancia expresiva al significado sobre la ambigüedad o ausencia plena del referente: el lenguaje artístico pasa de su condición de recurso mediante el cual el sujeto habla de la cismundaneidad o del mundo de la vida y se transforma en instrumento y condición de toda producción del mundo y su experiencia estética. En este sentido, reflexiones sobre el arte llevadas a cabo por Nelson Goodman en su texto Los lenguajes del arte, publicado en 1968, que además constituye una aplicación y un desarrollo riguroso de la filosofía analítica de Ludwig Wittgenstein, comporta un importante aporte para la aplicación hermenéutica en la estética. 
El fundamento de este giro se encuentra en los debates tanto de la fenomenología como de las teorías del Arte y la estética filosófica en las primeras décadas del siglo XX. Se trata entonces de dos problemas; 1) explicar el carácter de lo intencional como un actuar hacia. Es decir, se comprende la existencia de acontecimientos subjetivos (mentales) en los que no hay una finalidad empírica hacia un objeto o hacia un contenido, como es el caso del dolor que no presenta una orientación objetiva hacia, que no obstante, se expresan en el arte como expresados por una representación que puede explicar su intencionalidad. Dicho de otro modo, es lo que Jaakko Hintikka, en "Las intenciones de la intensionalidad" propone como la intencionalidad de los conceptos o de la conceptualidad. Por tanto, la conceptualidad del arte con la intencionalidad que la determina se presentan como interdependientes, a partir de lo cual se deduce la tesis: el mundo de las intenciones es también el de los conceptos y el mundo de los conceptos lo es de las intenciones. 2) De explicar la reflexión intencional de la multiplicidad de percepción como el conjunto de los datos sensoriales dados espontáneamente a nuestra conciencia, y que se específica en formas y representaciones (plásticos-visuales o conceptuales), en el ámbito de los procesos mentales o subjetivos, a través del juicio estético de los sentidos por el cual se distingue, se diferencian y se comparan las experiencias sensoriales acaecidas. La experiencia estética comporta una hermenéutica de los datos de la sensibilidad. De este modo se explica que todas las impresiones sensoriales directas se comprendan organizadas ya en categorías. "En esta perspectiva, el grado de sensación más primario que se pueda juzgar reflexivamente ya está orientado y organizado de modo que lo sea de objetos definidos" (Hintikka, 1980).

Podemos concluir que toda percepción y su correlato reflexivo es intencional en razón de su naturaleza dialógica y comunicacional; de otra parte, toda comunicación de información conlleva diferentes estados de cosas y procesos posibles al involucrar una distinción entre lo concordante con esa información y lo discordante con la misma. En este sentido se señala como la más viva característica de los lenguajes formales del arte, su propósito funcional y comunicativo y el intento continuo de hacer extensivo lo artístico y lo estético en la actividad discursiva. Umberto Eco advierte que el arte, en último término, "consiste en un diálogo entre personas concretas que puede dar forma al rapto pánico, pero siempre en su estructura comunicativa" (Eco, 1985:79). 
Es el caso de los proyectos Cow Parade, del artista Peter Haning en New York y de los proyectos Arborizarte, Animarte y Equuarte, organizados por la Fundación Corazón Verde en Colombia, en los que el arte entra en el género discursivo de la publicidad y se convierte ideológica y políticamente en un instrumento de propaganda y de manipulación. ${ }^{3}$ En estos constructos discursivos entran en función, además de los elementos retóricos, que pueden ser del tipo persuasivo o manipulatorio, "las tres pruebas de la enunciación, en el marco de un género discursivo particular [...] la organización textual se realiza a través de mecanismos de textualidad y de discursividad al servicio de la construcción de los tres sujetos discursivos: enunciador, enunciatario y el tercero, y de manera simultánea las tres dimensiones discursivas: ética, emotiva y cognoscitiva” (209).

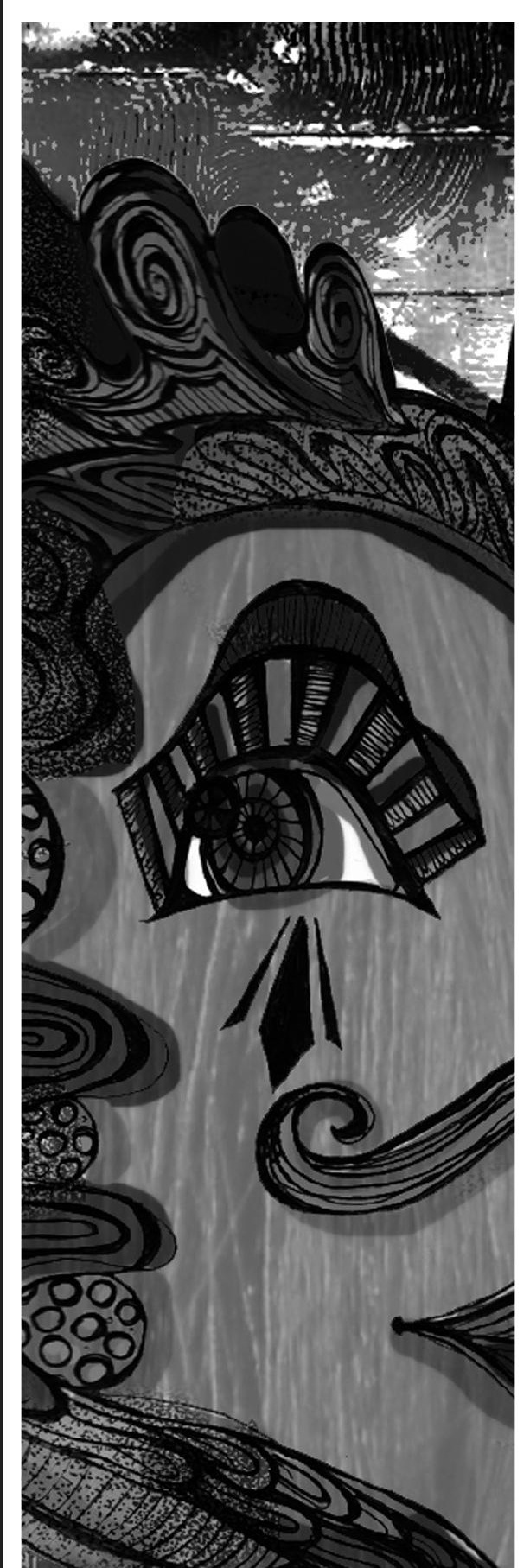

$\mathrm{Al}$ analizar este género discursivo no se pretende, como tradicionalmente se hace en las discusiones estéticas, develar una singularidad fenoménica, pero sí descubrir la orientación social enunciativa y la intencionalidad comunicativa dada por la "apariencia" de la imagen desde un discurso estético que no es mera imaginación. El tipo de análisis enunciativo del discurso artístico, nos dice que no se debe buscar en sus textos una esencia, sino ver en la misma forma los sentidos ideológicos, éticos, axiológicos y emotivos que en ella se expresan. Un análisis del texto artístico es siempre una interacción dialógica y ética en la medida en que pretende afectar y, en términos retóricos, adherir al espectador-interlocutor y enunciatario a los discursos que se encuentran ya naturalizados por un sentido común, como es el caso de estereotipos del género audiovisual (cine y televisión: dramatizados y subgéneros), el comics o en las enunciaciones del lenguajes del arte conceptual, fundando nuevos imaginarios (estilos) que al conformar y condicionar nuestras prácticas sociales permiten dar lugar a nuevas formas de configuración subjetiva e ideológica.

Considerando las producciones artísticas como parte de la discursividad social, y por tanto, como enunciaciones o discursos sobre el mundo, podemos advertir que los textos artísticos no son hechos puramente contemplativos. Su función y orientación es inseparable de su ética y de su responsabilidad, en el sentido preciso de un ethos cultural que se inscribe (conscientemente o no) en la obra, y del cual forman parte las valoraciones y la imagen que se tiene de sí mismo y del Otro, en cuanto espectador-interlocutor y enunciatario. Esto mediante una tonalidad por la cual la interacción dialógica artística afecta a la concepción que de sí misma tiene una sociedad: recuérdese las obras de Doris Salcedo, la instalación Sillas en homenaje a los magistrados y los muertos y desaparecidos en la masacre del Palacio de Justicia y, La Grieta, en la National Gallery de Londres, como una interpretación o lectura del resquebrajamiento de la nación y la sociedad colombiana.

En este contexto, la concepción bajtiniana es importante ya que se apoya en una interpretación social e histórica de los problemas del lenguaje y los géneros discursivos, que permite articular el conflicto social-humano manteniendo el rigor analítico de su especificidad. 
El signo estético como unidad de enunciación y la lengua, son para Bajtin, el resultado de la interacción social, en la objetivación del proceso de comunicación social. Significar supone conciliar la polisemia de la palabra y la imagen con un determinado significado, pero éste no está nunca cerrado puesto que comprender es siempre una actitud activa que habilita a una nueva significación en función del contexto situacional enunciativa. Podemos aplicar, sin temor a descontextualizar, el estudio de las transformaciones de la lengua, a las transformaciones en el lenguaje artístico plástico visual:

Los cambios históricos en los estilos (artísticos) están indisolublemente vinculados a los cambios en los géneros discursivos. La lengua literaria (diríamos y el lenguaje del arte) representa un sistema complejo de estilos; su peso específico y sus interrelaciones dentro del sistema (estético) de la lengua se hallan en un cambio permanente. La lengua de la literatura que incluye también los estilos de la lengua no literaria, representa un sistema aún más complejo y organizado sobre otros fundamentos. Para comprender la compleja dinámica histórica de estos sistemas, para pasar de una simple descripción de los estilos existentes e intercambiables a una explicación histórica de tales cambios, hace falta una elaboración especial de la historia de los géneros discursivos que reflejen todas las transformaciones de la vida social. Los enunciados y sus tipos, es decir, los géneros discursivos, son correas de transmisión entre la historia de la sociedad y la historia de la lengua (Bajtin, 1989: 253-254).

De este pasaje se puede afirmar la idea del enunciado como un elemento particular que, dentro de una configuración textual y semántica, como la plástico visual, permite construir un conjunto estable de enunciados que constituyen un cierto tipo de género discursivo y estilos, en los cuales, los sujetos discursivos al escoger los signos (unidades plástico - visuales de sentido) construyen los enunciados desde un nivel cognoscitivo y práctico que posibilita la naturaleza comunicacional del lenguaje artístico. Dicho de otra manera, se funda igualmente, en esta construcción estable de los enunciados, desde el análisis de la teoría de la enunciación dialógica, "la integración de las tres perspectivas de la argumentación:

1. La incondicionalidad de la intersubjetividad mediante la orientación del uno hacia la respuesta activa del otro y la relación valorativa que ambos establecen con un contenido o voz ajena (en este caso la obra). 2. Una nueva noción de contexto mediante la explicación de la organización estructural del enunciado donde el contexto se fusiona con las formas de manifestación del lenguaje, convirtiéndose en la parte semántica del enunciado (obra).

3. La interrelación entre las categorías de prácticas sociales humanas y su uso social del lenguaje para la definición de género discursivo” (p. 198). 


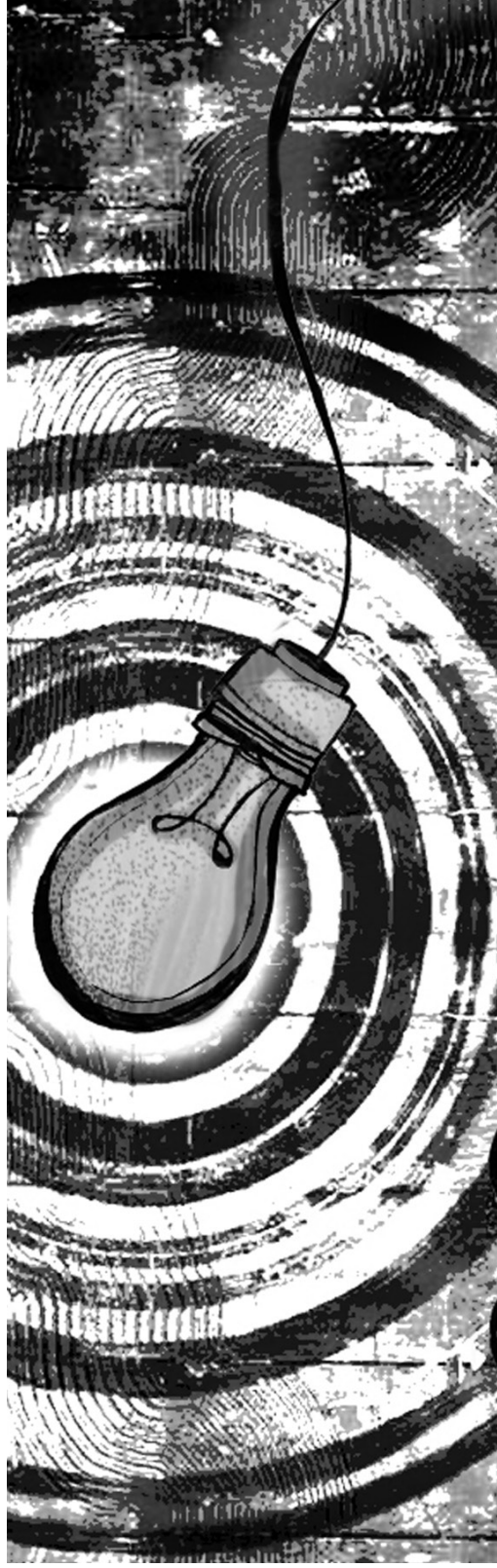

El discurso de las artes visuales -en tanto enunciados, según los géneros discursivos que contiene: cine, el video, el dibujo, el comics, diseño de animación gráfica, ${ }^{4}$ entre otros,- es un nivel en la estructura de la comunicación discursiva, en el que se conforman los signos de la interacción social. Bajtin concibe el enunciado como la unidad objetiva de la comunicación discursiva que adopta un carácter histórico concreto: "el lenguaje participa en la vida a través de los enunciados concretos que lo realizan, así como la vida participa del lenguaje a través de los enunciados" (1989:251). Los enunciados constituyen la forma a través de la cual los sujetos realizan, en la práctica social, el contrato social de comunicación, objetivándose en diversos modos particulares de la creación humana.

La realización humana, parecería ser, por tanto, el intento de asumir una conducta ética, en la que su mismo precepto se afirme, en el núcleo más íntimo de la personalidad y domine desde él toda la periferia de afectos y emociones, de deseos y de ideas, de un modo orgánicamente formado, como develamiento y devenir de la subjetividad del individuo. Pues, es allí donde aparece la esencia de la eticidad misma. La lucha por una forma de la vida que cuando se transforma en problemática para los ideales éticos, toma su forma en el arte y las formas de la estética: en el cine, el teatro, la pintura, las artes visuales en general. La representación estética del mundo de la vida, produce siempre una unidad en la experiencia sensible del arte, de la subjetividad y la conciencia "internas" con lo externo; una unidad de carácter y realización; una unidad entre la intención y la acción, siendo esta última la forma del arte, la apariencia sensible de una experiencia subjetiva. Condición necesaria del enunciado es la de estar orientado hacia otro. Hay en el autor en cuanto locutor una orientación subjetiva hacia otro que es espectador-interlocutor, hay un imaginario del otro donde se estructura el enunciado y sus enunciatarios, un autor-locutor y enunciatario que anticipa sus reacciones, considera sus perspectivas y se adelanta a las respuestas. En esta situación de enunciación las nociones de dialógico y polifonía aparecen como propiedades inherentes a todo enunciado; pues se encuentran en éste diferentes modos de la alteridad, intertextos, imágenes lejanas y voces de enunciados ajenos.

\section{El discurso visual y la representación enunciativa}

Las artes visuales -en tanto manifestación cultural- muestran y problematizan la realidad, en una dinámica estético-semántica de creación de modos de significados, sentidos y representaciones. Es decir, según diversos modos de enunciación. El discurso artístico pone en escena o situación enunciativa al mundo y al hacerlo se convierte en un espacio en el que toman forma los aspectos de la vida interior del autor y del héroe, sus tonos emocionales y cognoscitivos hasta la valoración del mundo externo mediante la ideología y sus juicios éticos. Los discursos visuales al tiempo que dinamizan los rasgos, socio-culturales de determinado período social, son en sí mismos una valoración, y como tal, construyen e integran los modos de enunciación y comunicación que le dan sentido a esa realidad. Este último aspecto resulta nuclear pues que es allí, en el mundo de las formas de la representación estética, donde se construye, según la hipótesis de Bajtin, "la totalidad temporal del héroe" que se funda en el "principio plástico-pictórico de ordenación del mundo objetual externo". 
El hombre en el arte es hombre integral... El hombre como valor plástico figurativo y el mundo que le es correlativo y que se combinan con él estéticamente transgreden una autoconciencia posible y real del hombre... La comprensión estética y la figuración del cuerpo externo y de su mundo son el don de otra conciencia (la del autor-observador con respecto al héroe), que no es una expresión suya desde adentro de él mismo, sino una actitud creativa y constructiva, que establece el autor en tanto que otro con respecto al héroe (Bajtin, 1989:123). ${ }^{5}$

La totalidad arquitectónica que corresponde a la visión artística, ordena tanto las instancias espacio-temporales como las del significado. La dimensión semántica del héroe adquiere una importancia estética central que se expresará en un conjunto diverso de elementos o signos plástico figurativos, vinculados simbólica y enunciativamente a la vida interior y el entorno humano y social del autor, que los ordena discursivamente en la objetivación de un tercero y voz ajena orientada a otro.

El Guernica, de Pablo Picasso deja ver la integración absoluta de cuerpo y alma, emoción y razón. Esta obra nos ilustra la operatividad de los componentes de la dinámica enunciativa en el lenguaje plástico-figurativo. El Guernica es la crónica de un acontecimiento histórico, el bombardeo a la población vasca de Guernica el 27 de abril de 1937. Es un relato, en el cual el discurso se expresa con pintura y dibujo. En esta obra los enunciados son directos, con un dibujo integrado a una totalidad de modo gráfico, muy similar al de una tira cómica. El primer elemento a destacar es la función del autor-interlocutor: la obra resulta de un encargo que el gobierno español ha hecho a Picasso en 1937 para pintar un mural a ser expuesto en el pabellón de la feria de París. Sin embargo, el tema o tópico lo motiva el bombardeo, diría Picasso, "las fuerzas reaccionarias que amenazan la libertad, la creatividad y la vida.” Es decir, hay una relación espaciotemporal vital en su discurso: la oposición política a la guerra civil española. El interlocutor-espectador será entonces, el pueblo español, el gobierno y el mundo occidental.

El primer boceto o enunciado es realizado el primero de mayo y la obra se terminará en la primera semana de junio, después de cinco semanas de trabajo diario. La historia del Guernica se narra por Picasso de muchas formas en un centenar de bocetos que conforman sus textos: los estudios del caballo y el toro, de las madres dolientes y las cabezas laceradas, donde cada uno constituye un enunciado y surgen múltiples enunciatarios. Un enunciado es una iconografía de sexo y violencia, en el toro, en el caballo herido, en la madre con el niño, en el guerrero caído.

Otro enunciado: el toro como la personificación del artista, Picasso y el caballo, el pueblo herido. Un tercer enunciado, es el dolor humano, en un espacio íntimo que expresa quizás, el rasgo de la privacidad del individualismo contemporáneo. 
Se hace evidente la integración de las tres tonalidades (Martínez, 2005: 205) y la orientación social y política del discurso plástico-figurativo, en las que, desde la intencionalidad del rechazo a la guerra, el enunciador hace énfasis con diversos enunciados como los ya señalados, pasa a la solidaridad como aliado de un pueblo inerme y enemigo del agresor y cada elemento enunciador, desde el dolor y la denuncia, convoca a la permanencia de la fuerza de la vida.

Los tonos emocionales y volitivos del autor, que establecen y crean la apariencia activamente como un valor estético, no se subordinan directamente al propósito semántico del héroe desde el interior sin la aplicación de la categoría valorativa y mediatizadora del otro; sólo gracias a esta categoría es posible hacer que la apariencia del héroe sea completamente abarcadora y concluyente, introducir el propósito semántico y vital del héroe en su aspecto exterior como en una forma, llenar de vida la apariencia, crear un hombre íntegro como un valor (Bajtin, 1989:90).

Son estos aspectos tonales que permiten, en un contexto plural dialógico, a un enunciado, una obra, o un texto alcanzar su significación estilística, "definido por su relación con otras réplicas de ese diálogo", que es a la vez un sentido de respuesta, a lo que ha sido dicho, pero también de anticipación a las posibles réplicas que han de producirse. De modo que lo que se consideraba propio de los géneros retóricos y de época, es aplicado por Bajtin a todos los discursos, los cuales están también orientados hacia el interlocutor-espectador y su respuesta. Un enunciado no se agota en sí mismo, no encuentra sus objetos en una relación unívoca, sino en la rica multivocidad. Lo importante de esta interpretación es que conlleva en la búsqueda de significación y de sentido "actual" de la multiplicidad, una apertura enunciativa plástica que se forma frente a cualquier objeto, en una compleja trama de relaciones, de valoraciones y a la pregunta por esa activa participación en el diálogo de las prácticas culturales en el cual todo enunciado visual se produce (Strawson: 1995).
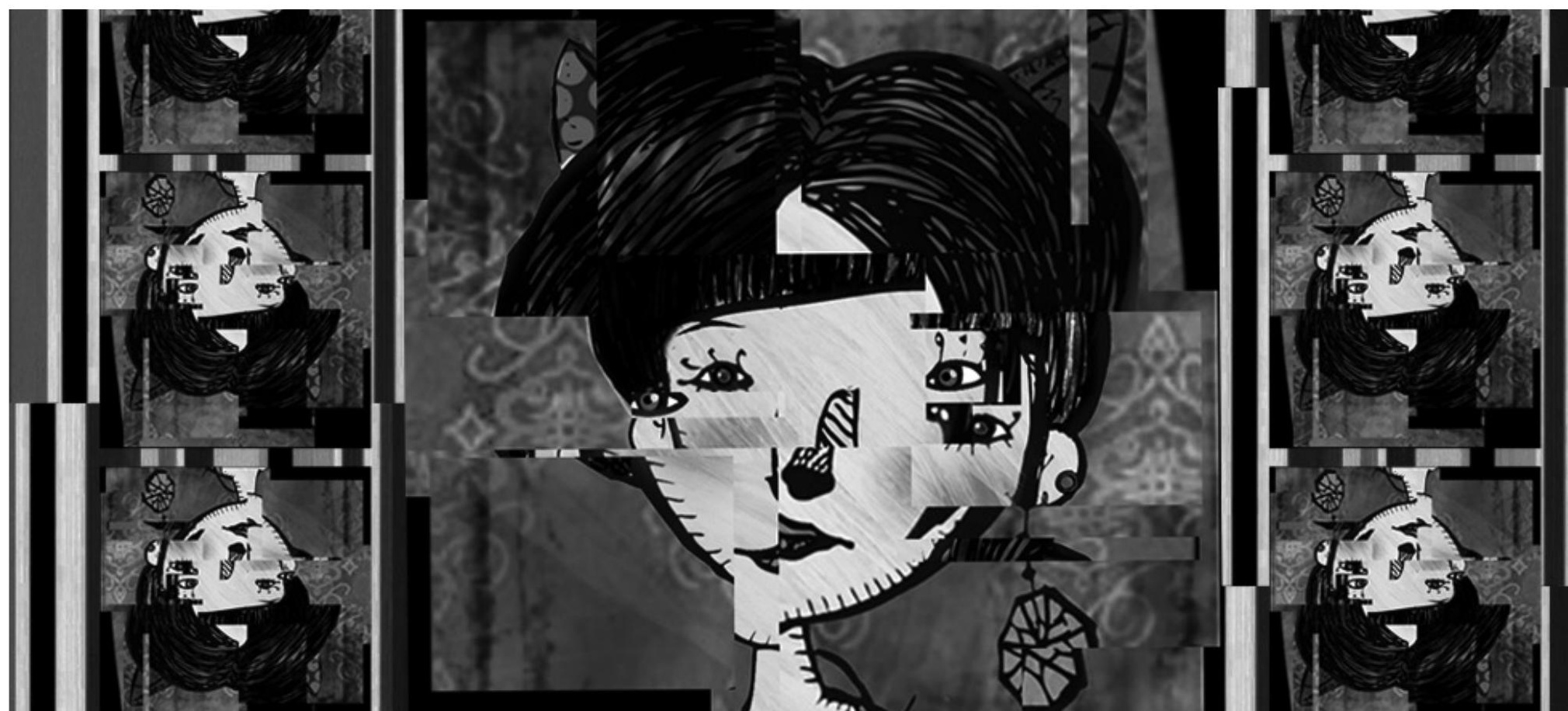


\section{El enunciado fílmico, autoría y valoración}

Aplicar al discurso cinematográfico los estudios teóricos sobre los géneros discursivos y la enunciación, no puede ser una actividad mecánica; requiere el análisis de las diferencias que hay entre un texto escrito y un texto o historia fílmica. El sujeto de la enunciación fílmica, dado mediante un desdoblamiento, siempre es empírico y su presencia en el texto es condicionada, incluso en el ámbito libre organizado del contrato comunicativo en el que actúa como receptor e interlocutor el espectador, por factores que se pueden identificar como:

1. El sistema de producción integral con productoras, directores y guionistas de reconocimiento e influencia socio-cultural.

2. El sistema de creación de estilos según géneros y autores (cine de géneros, cine independiente, cine rosa, lgtb \& queer, entre otros).

3. El sistema de creación de tipo documental y autorretrato documental con intención de mostrar objetivamente la realidad: documentales (testimonios o valoraciones en primera persona directa del mundo y la sociedad, historias reales, video arte) ${ }^{6}$.

En cualquier discurso cinematográfico hay un locutor-

enunciador implícito, que opera como segunda instancia del yo del autor, que puede enunciarse desde la trama y tópico, a través de un narrador, quien, a su vez, puede expresarse mediante diferentes enunciatarios encarnados por los personajes de la historia, voces en off y textos sobre el fotograma. Podemos valorar la creación cinematográfica como una obra artística autónoma, posible de producir un texto (objeto de análisis textual) que sustente sus sentidos y significaciones en estructuras discursivas (análisis de los géneros discursivos), desarrolladas a partir aspectos plástico figurativos y sonoros que producen un efecto particular sobre el espectadorinterlocutor (análisis de las tonalidades emocional y volitivas). De este modo la obra estará contenida en una historia de los cambios del lenguaje cinematográfico, de los géneros, los estilos y su desarrollo, del mismo tipo de los de la lengua de la literatura, donde, como afirma Bajtin: "Los enunciados y sus tipos, es decir, los géneros discursivos, son correas de transmisión entre la historia de la sociedad y la historia de la lengua" (1989:254).

Una categorización que nos permita alcanzar una visión arquitectónica de los sujetos de la enunciación y aplicar un aparato conceptual apropiado a las necesidades de un estudio del discurso fílmico-audiovisual, se puede presentar, en términos generales como sigue: (Aumont et all, 1995) 
Componentes de una situación de enunciación del discurso fílmico y sus aspectos relacionales:

\section{Aspectos objetivos}

- Un discurso y su estructura: la premisa, la historia, el guión y el argumento (análisis discursivo de los enunciados).

- Un contexto de producción y recepción: comercial, científico, artístico y documental (análisis del contexto de enunciación).

- Gramática plástico - visual de los recursos expresivos, textuales y enunciativos (fotograma, tipo de imagen, planos de cámara, escena, montaje, sonido, iluminación, colores).

\section{Aspectos no objetivos}

- Situación de enunciación fílmica, estilo y punto de vista óptico o cámara ${ }^{7}$ (análisis discursivo).

- Valoración de las tonalidades (elementos subjetivos).

- Juicios críticos del enunciador, enunciatario y afirmación del tercero.

\section{Componentes}

- Enunciatario testigo: representa la mirada objetiva directa, en la cual se establece una relación de equilibrio, entre el enunciador y el enunciatario que se mantienen en un plano de igualdad. Esta relación se presenta como la afirmación de un tú frente a un yo igualmente afirmado.

Esta mirada objetiva, responde a un enunciador que mira y hace mirar.

- Enunciatario visor: desde el ojo de la cámara constituye el mecanismo visual del tercero, por el cual se produce una mirada objetiva irreal, en la cual, se opera una fusión entre un enunciatario e interlocutor tú combinado con un enunciador y locutor yo que produce en estado de extrañamiento o simpatía en el que se pierde el principio de realidad del espectador-interlocutor. Esto se representa por la intervención activa y ajena del espectador ante la imagen fílmica.

- El personaje ausente o la no persona. Con este procedimiento se realiza un efecto de distanciamiento que se da en una relación de interpelación entre un enunciatario tú frente a un enunciador yo que se condensa con un tercero él. El es caso de Esperando a Godot, de Samuel Becket en el teatro, como también del cine de Woody Allen. ${ }^{8}$

- Enunciatario personaje: en este se integran de modo polifónico la mirada subjetiva de un enunciatario tú vinculado intrínsecamente con un tercero o él ante a un enunciador yo que se afirma. Se produce aquí la mirada subjetiva, que desde el autor, guionista y productor se concreta mediante el punto de vista de la cámara. 
Es por lo tanto en su conformación textual -como toda historia, aun en su mayor condición testimonial y autorretrato documental- la que nos lleva al análisis de los aspectos que organizan el discurso y que, a su vez, configuran esquemas de percepción e interacción a partir de los cuales los sujetos interpretan el mundo. La historia (diégesis) habilitada por la situación de enunciación, por la interacción entre enunciador, enunciatario, locutor e interlocutor, espectáculo y observador, entre otros aspectos del discurso del arte debe ser leída y analizada en función del efecto de realidad que el discurso produce. Los enunciados visuales del cine y la televisión, el video documental, en general, operan como escuelas de reproducción de la cultura, de valoraciones sociales y políticas, de educación afectiva y sentimental, estética y gestual que estipulan lo permitido y lo prohibido, validan costumbres y producen la desaparición o negación de otros géneros o estilos. Para decirlo de otro modo, el discurso visual (televisivo, teatral, cinematográfico, performático y gráfico) intertextúa y reconforma los estereotipos socio-culturales de cada época, dejando como huellas las representaciones que conforman esos imaginarios socio-históricos. Y logra construir y proponer, en la dinámica social discursos plásticovisuales anti-hegemónicos, como es el caso del cine independiente, del documental de ensayo, del cine étnico y de género, que, desde un punto de vista criticó una férrea resistencia a un discurso único y totalizante de la realidad.

La dimensión significante del enunciado visual, los modos en que en la imagen se condensa la articulación espacio-temporal, dicho de otro modo, aquello que Bajtin denominó como el cronotopos ${ }^{9}$-en tanto que herramienta conceptual para entender el modo en que la novela construye estructuras espacio-temporales que evocan pero no reflejan la subjetividad realpuede hacerse extensivo al lenguaje cinematográfico.
El cronotopo $($ crono $=$ tiempo, topo $=$ espacio $)$ o unidad de significación espacial y temporal conforma una figura conceptual y, para el discurso cinematográfico y plástico-visual un procedimiento que integra los elementos espaciales, como enunciación, forma o ámbito de una mirada que surge de los planos del ojo de la cámara: abierto, cerrado, grande, pequeño, global, fragmentario, entre otros, con los temporales: infinito, limitado, largo, corto, continuo, interrumpido, entre otros. Estos elementos aportan efectividad y énfasis tonales emocionales, de tal manera que los enunciados visuales sean similares a las de nuestra experiencia cotidiana: por ejemplo, la fusión abierto + infinito puede producir la sensación de libertad en un campo libre, el cerrado + limitado puede significar presión, prisión y negación. ${ }^{10}$

En lo que atañe a la composición y enunciación temporal, aunque en la mayor parte de las obras cinematográficas la cronología lineal continua se sigue utilizando, esta lógica enunciativa del ordenamiento causal (encadenamiento continuo de sucesos), ha sido abandonada en los discursos fílmicos de los últimos años, por directores-autores que están experimentando otras formas narrativas, en un contexto y una sensibilidad contemporánea que implica transformaciones en la vivencia cotidiana y las nociones del tiempo. Se puede estudiar estos desarrollos discursivos del lenguaje cinematográfico, en obras como Memento, Christopher Nolan, 2000; 21 gramos, Alejandro González Iñarritu, 2003; Old Boy, Chanwook Park, 2003; 2046 Los Secretos del Amor, Wong Kar Wai, 2005, Mulholland Drive, David Lynch, 2001, entre otros. Este lenguaje fílmico recompone un cronotopos que revela la crisis del relato y la enunciación clásica, diríamos, tradicional del cine.

De acuerdo con lo dicho, se pueden aplicar aquí las nociones de Bajtin sobre los condicionales del uso del lenguaje tanto por sus reglas básicas, en cuanto sistema que garantiza su comunicabilidad y, también por la situación espacio-temporal e histórico-social en la que se produce. 
Este es un lugar de encuentro con una teoría de la intertextualidad, en la medida en que es en relación con la multiplicidad de voces del discurso cinematográfico, que las experiencias de vida pueden ser culturalmente construidas.

Igualmente se mantiene el principio fundante de la teoría del enunciado de Bajtin y de su noción de dialogicidad, es decir: un enunciado es dado por individuo y dirigido hacia un individuo. Ese sentido de orientación intencional, es lo que dota de sentido a las palabras, pues es en su relacionalidad construida que se reconoce todo el contexto situacional, así como las múltiples voces que pueblan el discurso plástico visual. De allí que afirme que lo característico y constitutivo del enunciado es su "orientación hacia alguien", un enunciado tiene autor y destinatario, y es justo lo que lo diferencia de las palabras y oraciones, unidades significantes que son por el contrario, "impersonales, no pertenecen a nadie y a nadie están dirigidas" (Bajtin, 1989: 285). En el constructo central de Bajtin los conceptos de polifonía y dialógico, están implicados por su noción de direccionalidad como "cualidad de dirigirse a otro" sin la cual, el enunciado no puede darse. De esta manera, es el carácter contextual, relacional e intencional del objeto de comunicación, en este caso la obra visual, lo que hace que los hombres estén signados por las palabras de otros. La voz ajena es más que simple mimesis o reproductividad, es un desarrollo creativo, es siempre semi-ajena, semi-propia. La comprensión está indisolublemente unida a una respuesta, sea de objeción o de consentimiento, comprensión que siempre considera pues, al hablante, de lo cual se desprende que toda comprensión es dialógica.

Notas

1 Candidato a Doctor en el Doctorado de Humanidades de la Universidad del Valle. Licenciado y Magister en Filosofía de la misma universidad. Estudios de Licenciatura en Literatura.

${ }^{2}$ Organizada por el Museo del Banco de la República en el primer semestre del 2008. El catálogo presenta un texto que puede definirse dentro del género discursivo expositivo didáctico. Los seis episodios, se titulan textualmente de forma triple: "1/ Primer episodio: Arte y gentilicios, 2/Segundo episodio: Los pioneros, 3/Tercer episodio: Muralismo e indigenismo/realismo y nacionalismo, 4/ Cuarto episodio: Un viraje hacia las corrientes internacionales en América Latina: Ruptura, 5/Quinto episodio: Del nacionalismo al internacionalismo y viceversa: La resistencia, 6/sexto episodio: Adopción de la abstracción geométrica.” Estos enunciados además de crear sus respectivos enunciatario conforman un cronotopos y una tonalidad que podríamos llamar racional y axiológica.

3 Un análisis de mayor desarrollo se puede leer en: Cerón Jaime, "El arte de la instrumentalización: eventos artísticos de propaganda”, Periódico Arteria. No 19, abril-julio de 2009

4 A este género pertenecen producciones o creaciones Los Simson, The Matrix, y las producciones de The Pixar, entre las que se cuentan, El barbero loco, la era del hielo, Schre. Es importante resaltar que ha habido creaciones que involucran los dos lenguajes cinematográficos, por ejemplo, ¿Quién mató a Roger Rabbit? y The matrix.

5 Véase igualmente la sección intitulada "El héroe como totalidad de sentido", Pág. 123

6 Ver: Schefer, Raquel. El autorretrato en el documental: figuras / màquinas / imágenes. Universidad del Cine, Ediciones Catálogo. Buenos Aires, 2008. En el caso de las formas discursivas del documental se puede consultar este sugerente texto de la autora e investigadora la estética del cine portuguesa.

7 El honor perdido de Katherina Blum (1975), de la directora Margaretha von Trotta, y codirigida por su esposo Volker Schlôndorff, se basa en un caso real en el que una mujer sospechosa de alojar a un terrorista es difamada por la prensa de derechas. Utilizando un estilo clásicamente claro, la narración juega intrincadamente con nuestra esfera de conocimiento, permitiéndonos simpatizar con la protagonista y, sin embargo, manteniendo cierta distancia respecto a sus emociones reales. Los cambios del punto de vista óptico enfatizan el modo en que los ciudadanos de la supuestamente libre Alemania se convierten en objetivos de la policía." Bordwell, David \& Thomson Kristin. El arte cinematográfico. Paidòs Comunicaciones-Cine, Barcelona, 1995. Págs. 486-487 
8 Al respecto véase el interesante trabajo, Ricoeur, Paul, "la enunciaciación y el sujeto hablante", en Sí mismo como otro, Madrid, Alianza Editorial, 1996. pp 18-36

9 En la estética de Bajtin el concepto de cronotopos designa la coexistencia absoluta del tiempo y el espacio, y principio orientador de toda composición discursiva. Ambas categorías remiten a las relaciones espacio temporales socialmente construidas que son asimiladas por el arte. Su utilidad radica en poner en relación los ordenamientos espacio temporales propios de la obra con los externos a ella, es decir, con el contexto social. Véase: Bajtin, Mijail, Teoría y estética de la novela, Madrid, Taurus, 1991. y Estética de la creación verbal, Siglo XXI, editores, México DF. 1989.

10 Para un estudio detallado sobre las relaciones espacio-temporales véase el texto ya citado de Bordwell, David \& Thomson Kristin. Capitulo 5 “La puesta en escena en el espacio y en el tiempo.” Págs. 145-183, en: El arte cinematográfico. Paidòs Comunicaciones-Cine, Barcelona, 1995. Págs. 486-487

11 Ver: Alvarez, Ramírez William. "La estética y la experiencia del mirar”, Revista Praxis Filosófica, No 7, Departamento de Filosofía de la Universidad del Valle. 1997.

En este texto se presenta una descripción, desde la experiencia de la mirada en el arte eurocentral, mediante la cual se puede explicar la disposición de los personajes en una pantalla condicionada por el orden del ojo de la cámara. Donde se construyen principios de composición espacial -que como configuración de un discurso- orientan el ojo-espectador, prescribiendo las instrucciones requeridas para leer la imagen. Esta práctica reguladora de la visión, está basada en la percepción central instaurada por la perspectiva desde el Renacimiento. El segundo principio de la mirada es la relación campo-fuera de campo (espacio visualizado y espacio oculto). El fuera de campo oculto opera como un enunciado implícito, de modo establece, mediante la mirada, un lugar para el espectador dentro de la composición espacial plástico visual: el ejemplo por excepción es el estudio de Velázquez en "Las Meninas", pintura en la cual se produce una relación campo-fuera de campo: hay un espacio oculto que es el espacio del espectador.

\section{Referencias}

Álvarez, RamírezWilliam. (1997). La estética y la experiencia del mirar. Revista Praxis Filosófica, No 7, 51-76.

Álvarez, X. Lluis. (1986). Signos estéticos y teoría. Crítica de las ciencias del arte. Barcelona: Editorial Antropos, Siglo del Hombre.

Aumont, J., Bergala, A. y otros. (1995). Estética del cine: espacio filmico, montaje, narración, lenguaje. Barcelona: Ediciones Paidós Ibérica.

Bajtin, Mijail. (1992). El marxismo y la filosofía del lenguaje. Madrid: Alianza Editorial.

(1989). Estética de la creación verbal. México D.F.: Siglo XXI, editores.

. (1997). Hacia una filosofía del acto ético. De los borradores y otros escritos. Barcelona: Anthropos editores y Editorial

Universidad de Puerto Rico.

Bordwell, David \& Thomson Kristin. (1995). El arte cinematográfico. Barcelona: Paidós Comunicaciones-Cine.

Cerón Jaime. (2009 abril-julio). El arte de la instrumentalización: eventos artísticos de propaganda. Periódico Arteria. No 19.

Eco, Umberto. (1985). La definición del arte. Bogotá: Planeta-Agostini.

Hintikka, Jaakko. (1980) Las intenciones de la intensionalidad. En: Hintikka, Macintyre, Winch y otros: Ensayos sobre explicación y comprensión (pp 9-40). Madrid: Alianza Editorial.

Hofmann, Werner. (1995). Los fundamentos del arte moderno. Una introducción a sus formas simbólicas. Barcelona: Ediciones Península. Kosuth, Joseph. (1977). La idea como arte. Documentos sobre el arte conceptual. Barcelona: Editorial Gustavo Gili.

Marchan, Fiz Simón. (1986). Del arte objetual al arte del concepto: 1960-1974. Madrid: (5ta edición) Ediciones Akal.

Martínez Solís, María Cristina. (2005). la orientación social de la argumentación en el discurso: una propuesta integrativa. Cali: Ediciones Cátedra UNESCO.

Martínez Solís, María Cristina. (2005). La construcción del proceso argumentativo en el discurso: perspectivas teóricas y trabajos prácticos. Cali: Ediciones Cátedra UNESCO.

Ricoeur, Paul. (1996). La enunciaciación y el sujeto hablante. En: Sí mismo como otro. (pp 18-36) Madrid: Alianza Editorial.

Schefer, Raquel. (2008) El autorretrato en el documental:figuras / máquinas / imágenes. Buenos Aires: Universidad del Cine, Ediciones Catálogo. Buenos Aires.

Stangos, Nikos. (1996). Conceptos del arte moderno. Madrid: Alianza Forma.

Strawson F., Peter. (1995). La valoración estética y la obra de arte. En: Libertad y resentimiento. (pp 151-164). Barcelona: Ediones Paidós Iberica e Instituto de Ciencias de la Educación de la Universidad de Barcelona.

Von Wrigth, G.H. (1971). Explanation and Understanding. Itaca: Cornell University Press.

Wittgenstein, Ludwig. (1994). Tractatus logico-philosophicus. Barcelona: Ediciones Altaya. S.A. 